\title{
Automatable Splicing Method for Steel Cord Conveyor Belts - Evaluation of Water Jetting as a Preparation Process
}

\author{
David Zaremba ${ }^{1, *}$ - Patrick Heitzmann ${ }^{2}$ - Ludger Overmeyer ${ }^{2}$ - Lennart Hillerns ${ }^{1}$ - Thomas Hassel ${ }^{1}$ \\ ${ }^{1}$ Leibniz Universität Hannover, Institute of Materials Science (IW), Germany \\ 2 Leibniz Universität Hannover, Institute of Transport and Automation Technology (ITA), Germany
}

The increased demand of mineral resources leads to worldwide application of incessantly longer conveying systems. The length between axes can amount to $15 \mathrm{~km}$ and more. Owing to manageable dimensions and weight, appropriate conveyor belts are produced in segments of up to $300 \mathrm{~m}$. Final assembly takes place at the conveyor system, where the multitude of segments is connected to a long conveyor belt. An important point in assembly preparation is the stripping of the steel cords, which is mainly carried out manually using rudimentary techniques. The optimization potential is high, since the adoption of automatable and application-oriented preparation methods can minimize the conveyor downtime and improve the joint quality.

In this study, the application of the pure water jet is investigated, since this selective stripping method offers a lot of potential for automation and the creation of rough surfaces. The objective was to determine if an efficient, homogenous and selective removal of the rubber is possible without damaging the zinc coating of the steel cords. Following a parameter study, the generated kerf geometries and surfaces were investigated. The stripped steel cords and zinc coatings were analyzed through the preparation of micrographs. Concluding, an evaluation about the qualification of water jetting as an automatable method for joint and repair preparation is made.

Keywords: steel cord conveyor belt, splicing, repair preparation, automation, water jetting

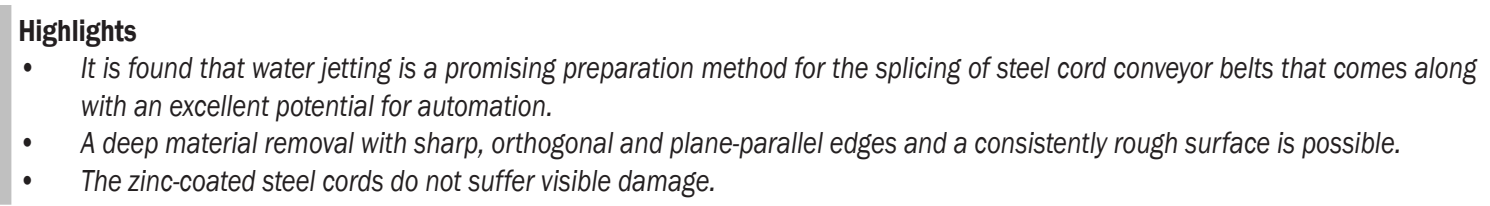

\section{INTRODUCTION}

The belt is one of the most important parts of a conveyor system when it comes to design and investment costs. Due to logistic reasons, the belt can only be transported in segments to the conveyor system, limited by weight or length of the individual segment. The splicing is done directly at the system. In the splice, tensile forces are transferred through the core rubber and not via tension member. This fact makes a splice the weakest point of a conveyor belt. The tension member of a belt can consist of textile fabric or steel cords, depending on the tensile strength of the belt. Steel cord conveyor belts can reach a nominal belt breaking strength up to $10.000 \mathrm{~N} / \mathrm{mm}$. Fig. 1 shows the general structure of a steel cord conveyor belt [1].

Current research to achieve a higher quality for splicing is mainly focused on optimization using FEM but neglects adhesion mechanisms and automation capability of the process [2].

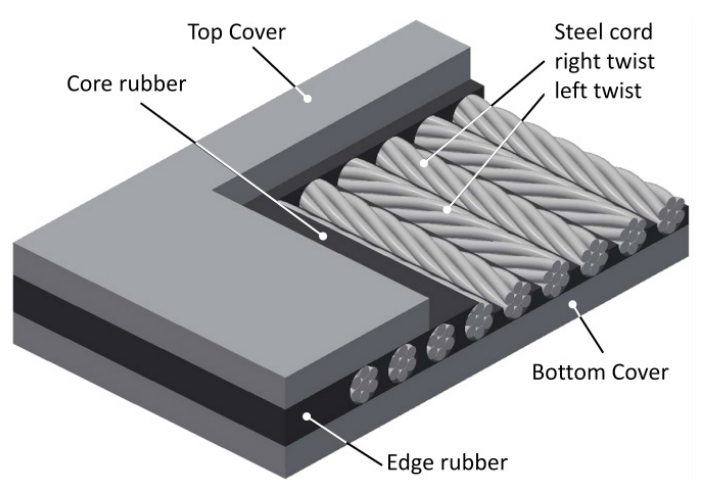

Fig. 1. Steel cord conveyor belt

\section{STEEL CORD CONVEYOR BELT}

The steel cords are covered in core rubber and form the carcass of the belt which is covered by top and bottom cover. The bottom cover transfers the driving forces from drive pulley to the belt. The top cover transports the bulk material and protects the carcass from damages caused by material impacts. The steel cords are right and left twisted and placed alternate next to each. The cords are zinc coated and have a 
zinc oxide layer on top. Zinc oxide has two effects during the belt fabrication. On the one side, it is a vulcanization accelerator and, on the other hand, it provides the basis for a zinc sulfide layer that occurs during vulcanization process between rubber and steel cords and leads to a better adhesion [3] and [4].

The splicing procedure of a steel cord conveyor belt is performed as follows. First, the splicing area needs preparation. Before assembling the vulcanization press, the new rubber has to be placed into the splice. Then the vulcanization of the splice area completes the splicing procedure. The present preparation process for splicing procedure consists of numerous manually performed steps. The steel cords of both ends of the conveyor belt have to be completely removed from rubber. Therefore, the first step is to remove top and bottom cover with an oscillating cutting edge. To cut the steel cords apart, a stripping machine is used. Then the biggest amount of the core rubber is stripped from the cords with piano wires.

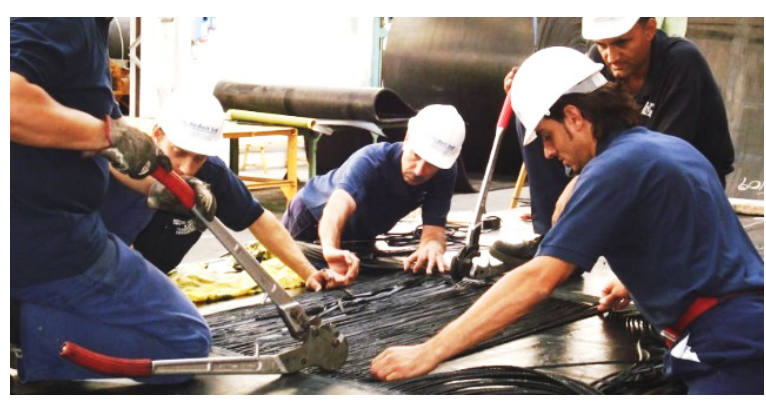

Fig. 2. Preparation process of a steel cord splice [RI-Belt Sud S.R.L]

As last step, cutting tools are used to remove the remaining amount of rubber and shorten the steel cords to the required length if necessary. Fig. 2 shows a splicing process. Then the cords have to be placed according to the splice layout, see Fig. 3. Then new core rubber has to be put between the steel cords. The total process is very time consuming due to its low level of automation and considerable number of manual work steps. The splicing quality can be primary defined through the adhesion between steel cords and core rubber. The fact that the zinc oxide layer of the steel cords is responsible for it, the layer must not be damaged during the preparation of the splicing procedure. To avoid damaging the zinc oxide layer is almost impossible due to the removal of core rubber just by cutting tools [1].

In this study, the application of the pure water jet is investigated, since this selective stripping method offers a lot of potential for automation and the creation of rough surfaces. Machining rubber with an erosive, pure water jet is a common method for cutting, cleaning and recycling purposes [5] to [7], so the application as a splicing preparation method is obvious. The objective was to determine if an efficient, homogenous and selective removal of the rubber is possible without damaging the zinc coating of the steel cords.

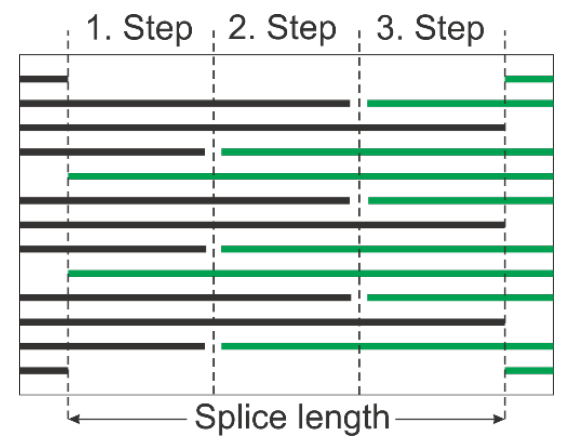

Fig. 3. Layout of a 3-step steel cord splice

\section{MATERIALS AND METHODS}

The investigations were carried out using a segment of an industrial steel cord conveyor belt with a thickness of $t=30 \mathrm{~mm}$, in new condition.

The material was vulcanized using "STG type" primer, rubber strips and cover plates (manufacturer: "Nilos"). The cover plate had a thickness of $t=15 \mathrm{~mm}$, the diameter of the zinc-coated steel cords was $d=8 \mathrm{~mm}$. Fig. 4 shows a sectional view of the test material.

All jetting experiments were carried out using a "Stein Moser WS0707" gantry-style

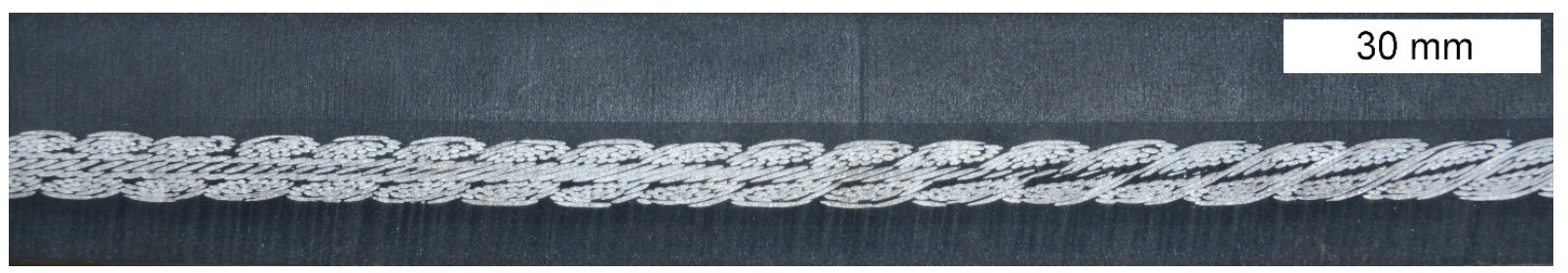

Fig. 4. Sectional view of the test material 
$(x, y, z)$-guiding machine. The high-pressure pump was a "BFT Servotron 40.37" (max. operating pressure $p_{w}=400 \mathrm{MPa}$, max. volume flow rate $\left.Q_{w}=3.8 \mathrm{l} / \mathrm{min}\right)$. The high-pressure valve applied was a "BFT WJ070060", modified to include a "Hammelmann" nozzle mount. Three flat-jet nozzles "Hammelmann Type R" with the jet angles $\alpha_{1}=10^{\circ}$, $\alpha_{2}=20^{\circ}$ and $\alpha_{3}=30^{\circ}$ were used alongside with sharpedged round-jet nozzles "Hammelmann Type I". The nozzle diameter was kept constant with $d_{0}=0.4 \mathrm{~mm}$. The nozzle coefficients were specified with $k_{f}=0.67$ for the flat-jet nozzles and $k_{r}=0.70$ for the roundjet nozzle by the manufacturer, respectively. The nozzles allowed for a maximum water pressure of $p=300 \mathrm{MPa}$. Because of the flexible material behavior of the rubber, the achieved kerf-depth- and surface-roughness values were measured optically using fringe projection technology (equipment manufacturer: "GF Messtechnik"), in five positions each respectively.

For a neutral comparison of the material removal profile and-efficiency, the optimum standoff distance was determined for each jet angle $\alpha$ to allow a material removal width of $b=10 \mathrm{~mm}$. Following, surface structure and -profile were analyzed. As different jet disintegration stages are present at the same jet width when using various jet angles, an influence on the material removal profile can be expected. For the round jet nozzle, staggered tool paths were used with variation of the tool path distance. The nozzles with the most promising results were picked for a more detailed parameter investigation, also including multiple material removal iterations. After parameter and procedure optimization, the conveyor belt was stripped down to its steel cords. A micro section was prepared in order to investigate if the formerly applied zinc coating was still intact.

\section{RESULTS AND DISCUSSION}

Initial experiments showed that the utilized round jet nozzles did not allow a consistent material removal of the belt rubber. Similar to nozzle types used for cutting applications, they generate a coherent and narrow jet with a characteristically high energy density on a small contact area. Although this kind of nozzle is well suited for precise material removal of other composite materials (e.g. CFRP [8] to [10]), the elastic flexibility of the rubber effected a bending of the material away from the jet. This resulted in lamellar surfaces, combined with a comparatively low material removal rate. The results obtained using flat-jet nozzles were considerably better. As expected, different surface profiles were generated dependent on the jet angle. While the flat-jet nozzles with $\alpha_{1}=10^{\circ}$ and $\alpha_{2}=20^{\circ}$ produced a straight surface profile with a consistent surface roughness, the surface profile generated by the nozzle with $\alpha_{3}=30^{\circ}$ was accentuated in the edges and less consistent. Through a furthermore lower material removal rate compared to $\alpha_{1}=10^{\circ}$ and $\alpha_{2}=20^{\circ}$, the jet angle of $\alpha_{3}=30^{\circ}$ did not implicate applicable advantages and was therefore rejected from the following investigations. Fig. 5 shows a consistent material removal path of a flat jet nozzle with $\alpha_{1}=10^{\circ}$ and $p=100 \mathrm{MPa}$.

As displayed in Fig. 6, achieved kerf depths for $\alpha_{1}=10^{\circ}$ were slightly higher than for $\alpha_{2}=20^{\circ}$. Measured surface roughness was significantly higher for the narrower jet angle. Since higher surface roughness goes along with an increased surface area,
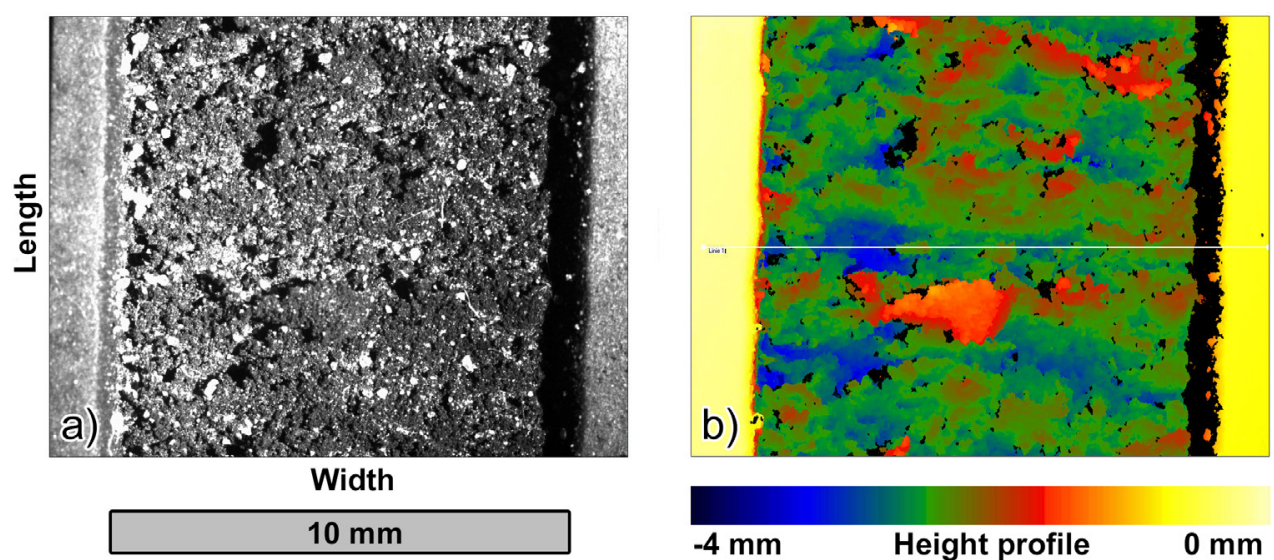

Fig. 5. Surface topography in a) camera view and b) height profile (fringe projection) of a material removal path generated by a nozzle with $\alpha_{1}=10^{\circ}$ and $p=100 \mathrm{MPa}$ 

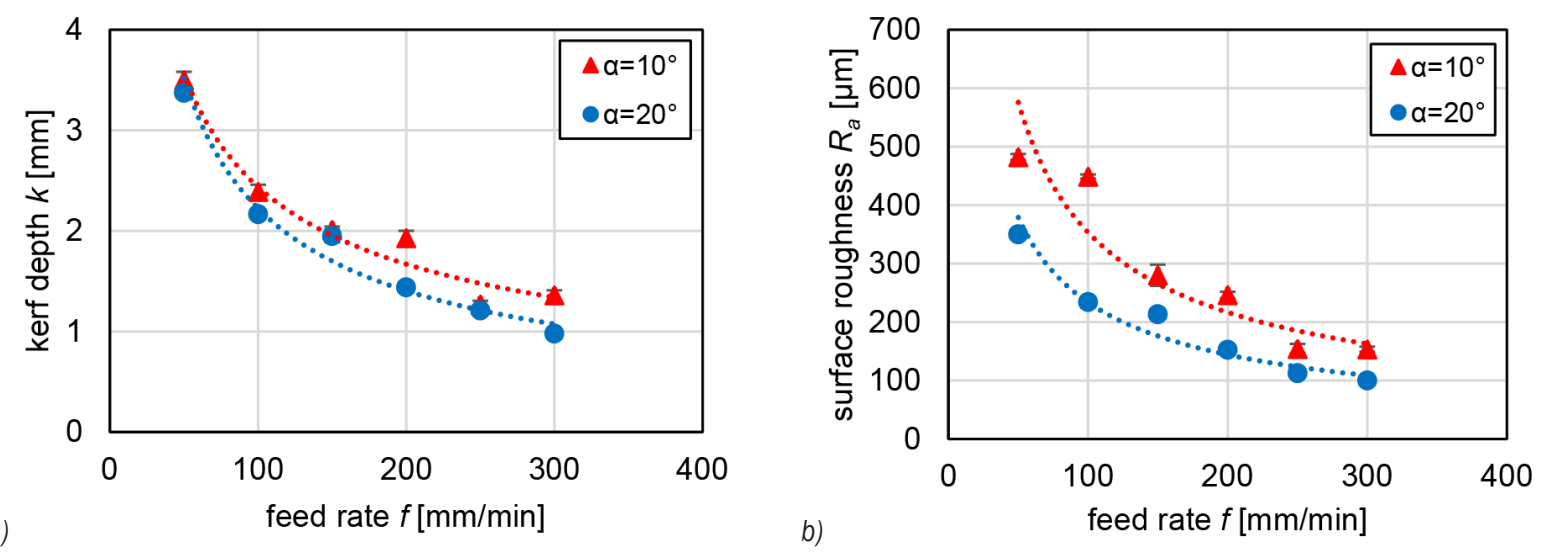

Fig. 6. a) Kerf depth $k$ and $b$ ) mean surface roughness index $R_{a}$ compared to the feed rate $f$ for a kerf width of $b=10 \mathrm{~mm}$

this can be advantageous when it comes to priming and splicing. Therefore, a higher surface roughness is generally preferable. A noteworthy fact is that the utilized flat-jet nozzles required a higher water volume flow rate than the stated nozzle coefficient of 0.67 would let guess. The available water volume flow rate of $Q_{w}=3.8 \mathrm{l} / \mathrm{min}$ was almost consumed at $p=150 \mathrm{MPa}\left(\alpha_{1}=10^{\circ}\right)$ and $p=200 \mathrm{MPa}\left(\alpha_{2}=20^{\circ}\right)$. For this reason, the stated pressure levels were set as the maximum values for each test series, respectively. As expected for an appropriate parameter study, kerf depth and surface roughness increase with an elongated contact time (smaller feed rate). As displayed in Figs. 7 and 8, the achievable kerf depth increases straight proportional to the quantity of iterations for both jet angles. Using the test setup, a total of $n=4$ iterations was necessary to completely remove the top cover and strip the steel cords at a feed rate of $f=100 \mathrm{~mm} / \mathrm{min}$. For $\alpha_{1}=10^{\circ}$ a water pressure of $p=150 \mathrm{MPa}$ was necessary, for $\alpha_{2}=20^{\circ}$ a water pressure of $p=200 \mathrm{MPa}$. In both cases, the real water volume flow rate is expected to be similar close to $Q_{w}=3.8 \mathrm{l} / \mathrm{min}$, recognizable by the pump's maximum workload. Furthermore, it was found that the surface roughness remains constant independent of the iteration quantity. The test equipment allowed for maximum surface roughness values of $R_{a 1}=480.9 \mu \mathrm{m}\left(\sigma_{1}=5.3 \mu \mathrm{m}\right)$ for $\alpha_{1}=10^{\circ}$, $p=150 \mathrm{MPa}$ and $R_{a 2}=465.7 \mu \mathrm{m}\left(\sigma_{2}=6.2 \mu \mathrm{m}\right)$ for $\alpha_{2}=20^{\circ}, p=200 \mathrm{MPa}$, respectively. Both jet angles were likewise found suitable for the application, with advantages regarding equipment wear which can be expected for the lower necessary pressure at $\alpha_{1}=10^{\circ}$.

Fig. 9 shows two photographs after removal of the cover plate and stripping the steel cords by water jetting and following drying by compressed air, as
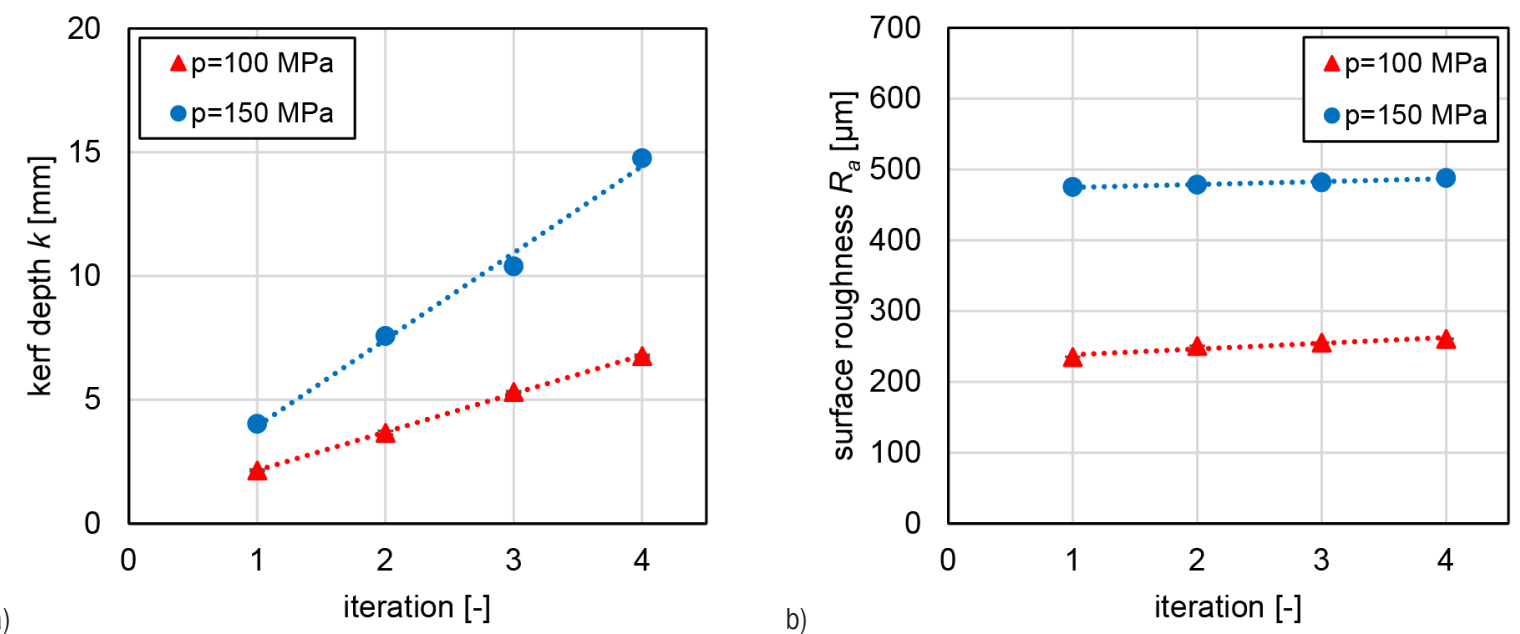

Fig. 7. a) Kerf depth $k$ and $b$ ) mean surface roughness index $R_{a}$ compared to water pressure $p$ for iterative material removal procedure, a jet angle of $\alpha=10^{\circ}$ and a feed rate of $f=100 \mathrm{~mm} / \mathrm{min}$ 

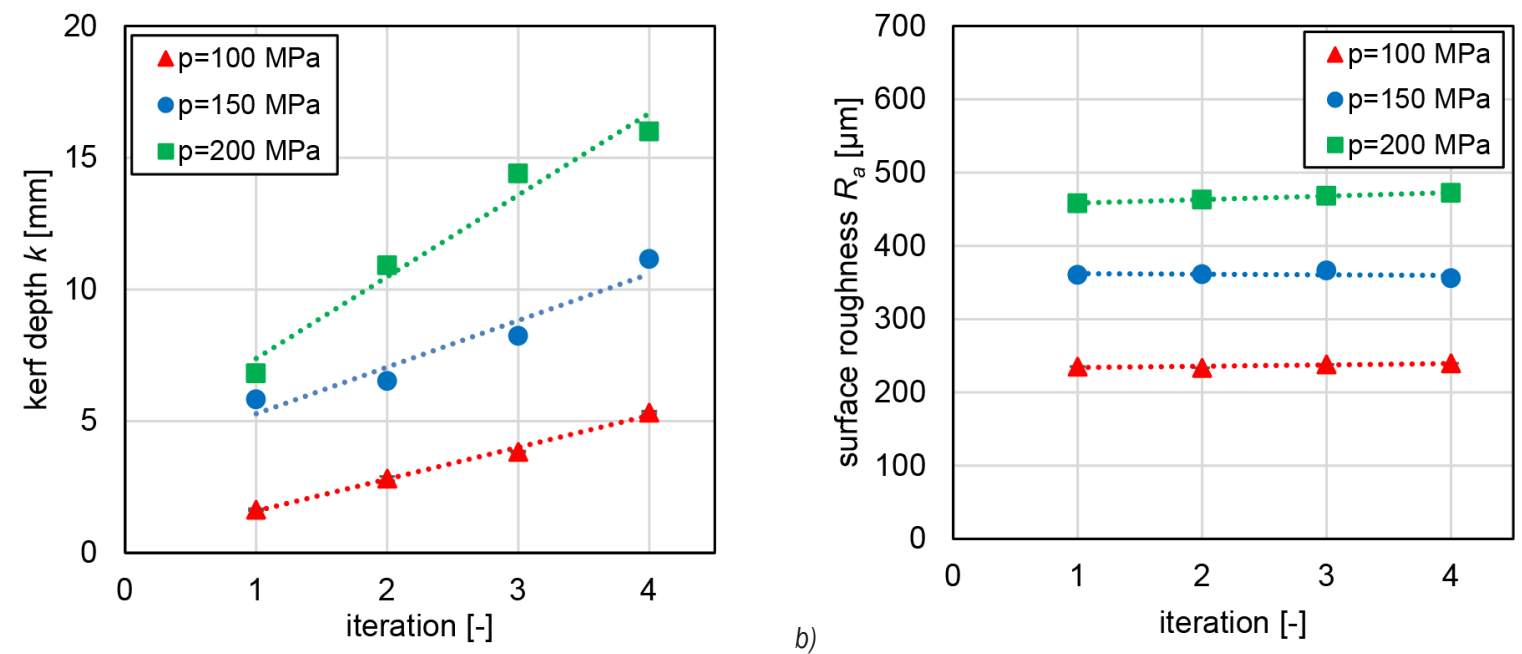

Fig. 8. a) Kerf depth $k$ and $b$ ) mean surface roughness index $R_{a}$ compared to water pressure $p$ for iterative material removal procedure, a jet angle of $\alpha=20^{\circ}$ and a feed rate of $f=100 \mathrm{~mm} / \mathrm{min}$

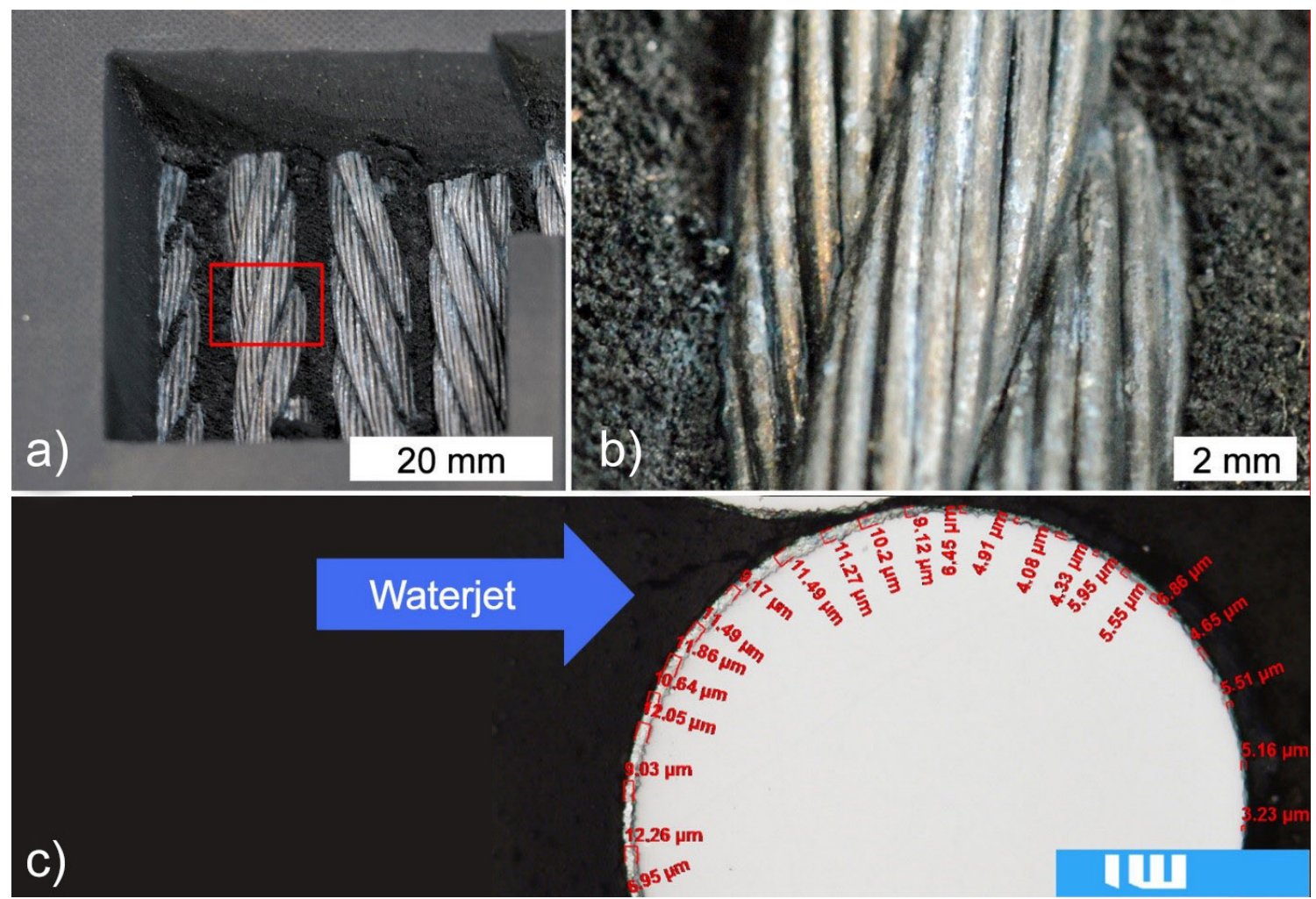

Fig. 9. Stripped steel cords after iterative removal of the a) cover plate, b) detail view, and c) micro section of a stripped cord with measurements of the zinc coating thickness

well as a micro-section of a single cord wire. It shows that a deep material removal with sharp, orthogonal and plane-parallel edges is possible with the utilized equipment (Fig. 9a). The exposed zinc-coated steel cords do not suffer visible damage (Fig. 9b). The prepared micro-section of a stripped cord shows that the galvanized zinc coating is still visible on the waterjet-treated side (Fig. 9c). The thinner coating on the opposite side originates from the wire production method (wire drawing); this appearance can also be found on new condition steel cords. 


\section{CONCLUSIONS AND OUTLOOK}

Concluded, water jetting is a promising preparation method for the splicing of steel cord conveyor belts that comes along with an excellent potential for automation. Utilizing commercially available pump technology combined with flat-jet nozzles, stripping rubber of the steel cords is easily possible in high quality without visible damage of the zinc coating.

Besides the effect on splice quality, the described preparation process offers further improvement opportunities. Material removal rate and surface roughness are further expected to be increased through bigger water volume flow rates, which go along with an increase of hydraulic power. Appropriate technology is available in the market and will be utilized by the authors for further investigations. Considering the behavior of load transmission in a steel cord belt splice, it becomes apparent that it mainly takes place at the lateral cord flanks. Unlike this, the preparation method described in this paper only includes the top- and bottom machining of the belt (cf. Fig. 10a). Therefore, future investigations should also include 3D machining processes $\mathrm{cf}$. Fig. $10 \mathrm{~b}$.

Current splicing preparation applications used in industry furthermore include both the complete stripping of the steel cords (cf. Fig. 11a), and the leaving of a residual rubber layer on the cords ( $\mathrm{cf}$. Fig. 11b). Some manufacturers' perception is that the first bonding between the zinc coating and the rubber offers better adhesion quality than a later bonding, other manufacturers prefer the fabrication of a clean splicing through completely stripping the cords from old rubber.

These procedures are however based on practical experiences made by the individual manufacturers. Future work should therefore include an independent investigation of both variants under consideration of the present adhesion mechanisms. The splicing preparation method presented in this paper however offers a lot of potential for both variants. Alongside the damage-free, complete stripping of the steel-cords, which offers superior quality compared to conventional cutting tools, a consistently rough rubber surface is generated when leaving a rubber layer on the steel cords. This rough rubber surface comes along with a larger contact surface for following vulcanization processes. Compared to the flat surfaces, which are generated through the conventional preparation techniques as described before, the application of this technology does not only offer a lot of potential to reduce downtime and splicing duration through automation, but also to improve the adhesion quality. As shown in Fig. 11c and d, the adaption of water jetting as a preparation process offers new layout possibilities through the integration of textures, which may further support adhesion quality. The effect on quality and reproducibility of appropriate belt splicing has to be analyzed in further investigations.

Following the described optimization of the preparation and splicing processes, an application in form of automatable preparation- and splicing machines is likely.

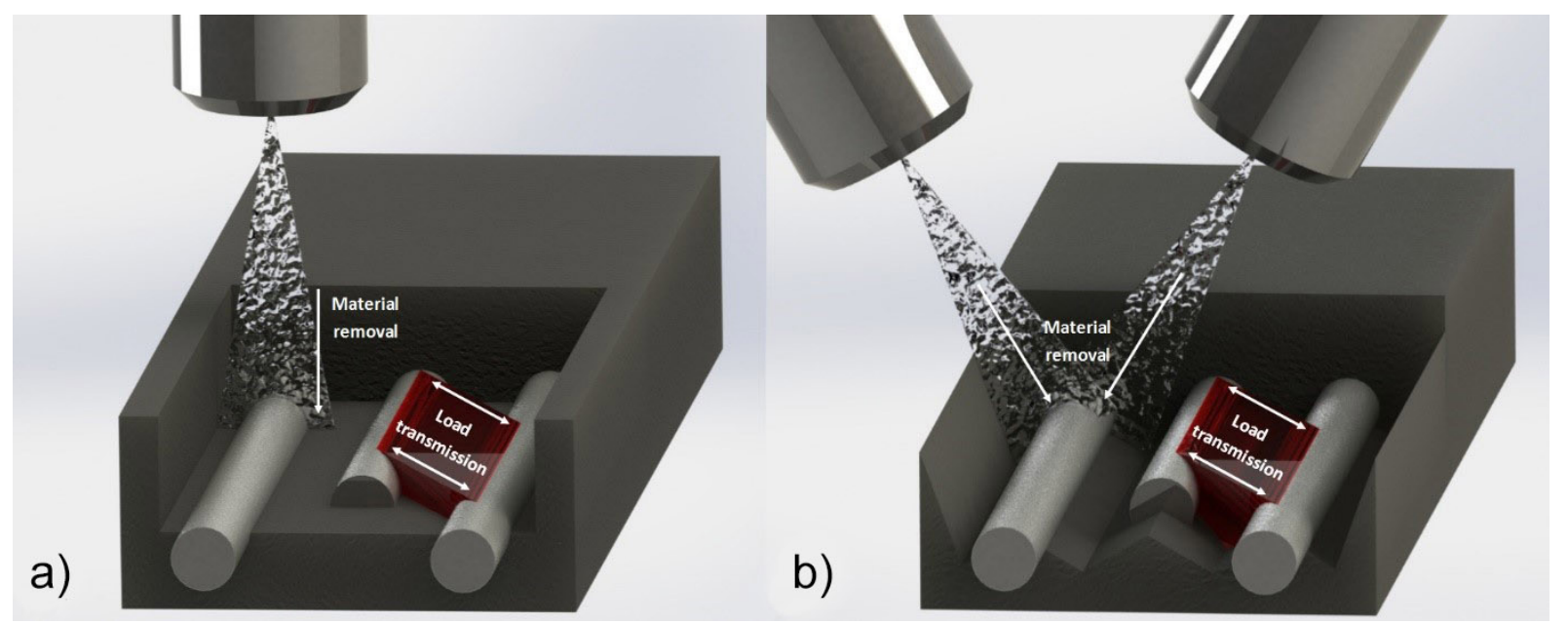

Fig. 10. Direction of load transmission and material removal for a) $2 D$, and b) $3 D$ machining 

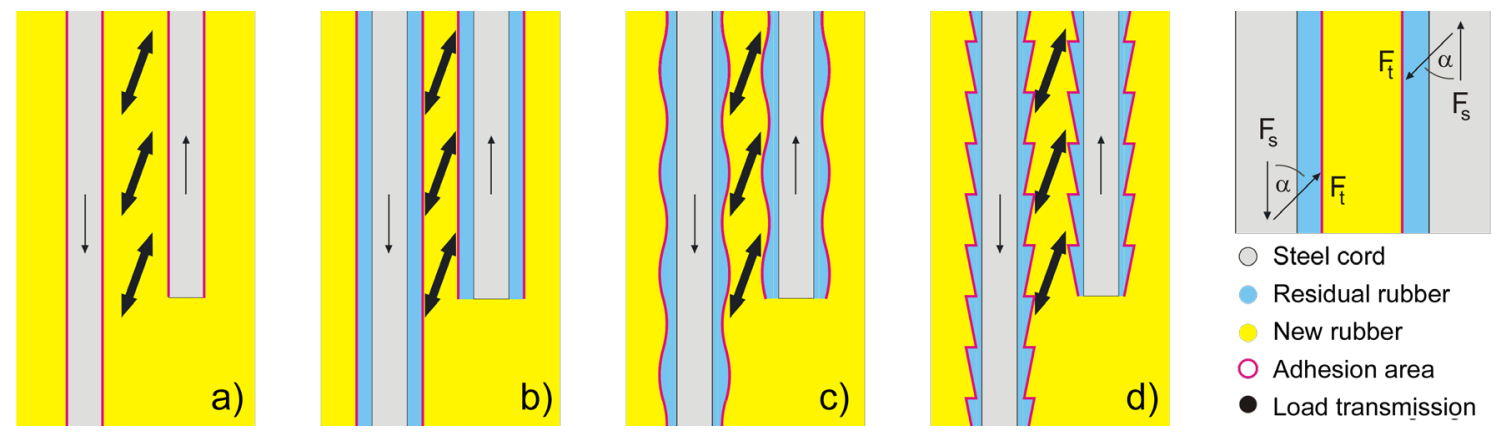

Steel cord

- Residual rubber

New rubber

O Adhesion area

d)

Load transmission

Fig. 11. Schematic splice illustration for different splicing preparation layouts for steel cord conveyor belts; a) complete stripping of the cords, b) remaining residual rubber layer with defined thickness and c) and d) systematic texturing of the residual rubber layer

\section{ACKNOWLEDGEMENTS}

The authors thank the Institute of measurement and automatic control (IMR) for providing the fringe projection instrumentation and the German working group of waterjet technology (AWT) for fruitful discussion.

\section{NOMENCLATURE}

$\alpha \quad$ jet angle, $\left[{ }^{\circ}\right]$

$b \quad$ kerf width, [mm]

$d$ diameter, [mm]

$d_{0} \quad$ orifice diameter, [mm]

$f \quad$ tool feed rate, $[\mathrm{mm} / \mathrm{min}]$

$k \quad$ kerf depth, [mm]

$k_{f}, k_{r} \quad$ nozzle coefficient, [-]

$n \quad$ iteration count, [-]

$p \quad$ water pressure, $[\mathrm{MPa}]$

$Q_{w} \quad$ water volume flow rate, $[1 / \mathrm{min}]$

$R_{a} \quad$ mean roughness index, $[\mu \mathrm{m}]$

$\sigma \quad$ standard deviation, $[\mu \mathrm{m}]$

$t \quad$ material thickness, $[\mathrm{mm}]$

\section{REFERENCES}

[1] Ziller, T., Hartlieb, P. (2010). Fördergurte in der Praxis - Know How and Know Why. NILOS GmbH \& Co. KG, VGE Verlag $\mathrm{GmbH}$, Essen.

[2] Froböse, T.; Heitzmann, P.; Wakatsuki, A.; Overmeyer, L. (2014). Entwicklung eines FE-Modells zur Optimierung von Stahlseil-
Fördergurtverbindungen. Logistics Journal: Proceedings, vol. 2014, no. 1, D0l:10.2195/Ij_Proc_froboese_de_201411_01.

[3] Sönksen, H. (1987). Korrosionsschutz von Seilen als Zugträger in Fördergurten. PhD Thesis, University of Hannover, Faculty of Mechanical Engineering, Hannover.

[4] Rzymski, W., Wolska, B. (2005). Unkonventionelle Vernetzung ausgewählter Elastomere. Gummi Fasern Kunststoffe, vol. 58, no. 6, p. 358-363.

[5] Raghavan, C., Olsen, J.H. (1993). Airport runway cleaning method and apparatus. United States Patent and Trademark Office, US5228623 A.

[6] Weide, H.G., Kikels, R., Hänisch, G. (2016). WasserkreislaufAnhänger für Landebahnreini-gung mit HochdruckReinwasserstrahl. 50. Arbeitskreis Wasserstrahltechnologie, Hannover.

[7] Spur, G., Stöferle, T. (1987). Handbuch der Fertigungstechnik. Band 4/1, Abtragen/ Beschichten. Carl Hanser Verlag, München, Wien

[8] Zaremba, D., Wachsmuth, S., Schneider, P., Hufenbach, W., Maier, H.J., Hassel, T. (2014). Method for the material-specific repair preparation of carbon fiber reinforced plastic structures. Proceedings of the $22^{\text {nd }}$ International Conference on Water Jetting, Haarlem.

[9] Zaremba, D., Biskup, C., Heber, T., Weckend, N., Hufenbach, W., Adam, F., Bach, Fr.-W., Hassel, T. (2012). Repair preparation of fiber-reinforced plastics by the machining of a stepped peripheral zone. Strojniški vestnik - Journal of Mechanical Engineering, vol. 58, no. 10, p. 571-577, D0l:10.5545/svjme.2012.305.

[10] Hufenbach, W., Adam, F., Heber, T., Weckend, N., Bach, Fr.-W., Hassel, T., Zaremba, D. (2011). Novel repair concept for composite materials by repetitive geometrical interlock elements. Materials, vol. 4, no. 12, p. 2219-2230, DOl:10.3390/ma4122219. 